\title{
Associations between serum 25-hydroxyvitamin D and sleep, as estimated by actigraphy and the Pittsburgh Sleep Quality Index (PSQI)
}

\author{
A.L. Darling ${ }^{1}$, K.H. Hart ${ }^{1}$, S. Arber ${ }^{2}$, B.A. Middleton ${ }^{1}$, P.L. Morgan ${ }^{1}$, S.A. Lanham-New ${ }^{1}$ and \\ D.J. Skene ${ }^{1}$ \\ ${ }^{1}$ School of Biosciences and Medicine and ${ }^{2}$ Department of Sociology, University of Surrey, Guildford, GU2 $7 X H$
}

It is unknown whether vitamin D status affects sleep health, but recent studies suggest vitamin D deficiency is associated with shorter sleep duration ${ }^{1}$ and lower sleep efficiency ${ }^{2}$. This study investigated whether there is a relationship between vitamin $\mathrm{D}$ status and sleepwake cycles in UK dwelling South Asian (SA) and Caucasian (C) women, using ambulatory actigraphic data and self-reported sleep quality data from the D-FINES II (Vitamin D, Food Intake, Nutrition and Exposure to Sunlight in Southern England II) study. In June-August 2010, serum 25-hydroxyvitamin D [25(OH)D] and data on self-reported musculoskeletal pain were collected from $\mathrm{n}=47$ women. In September-October 2010, participants wore Actiwatch-L (AWL, Cambridge Neurotechnology) monitors on their wrists for $24 \mathrm{~h} /$ day, over 14 consecutive days to measure sleep-wake activity as well as completing the PSQI (self-reported sleep quality) once. A subset of $n=37$ women also wore an AWL on a neckband during the daylight hours to measure environmental light exposure. Each subject's actigraphic data (including light exposure) were eligible to be included in the statistical analysis if they had $\geqslant 7$ days of valid data and a 25(OH)D measurement. Relationships between $25(\mathrm{OH}) \mathrm{D}$ and actigraphic measures were analysed by Pearson's bivariate correlations, as well as by partial correlations to control for potential confounders. PSQI scores are ordinal data so relationships were analysed by Spearman's correlations only.

There was a significant negative relationship between $25(\mathrm{OH}) \mathrm{D}$ concentration and actigraphic sleep latency in SA $(\mathrm{r}=-0 \cdot 562, \mathrm{P}=$ 0.036), and a significant positive relationship between $25(\mathrm{OH}) \mathrm{D}$ and both overall PSQI score $(\mathrm{r}=0.385 \mathrm{P}=0.047)$ and $\mathrm{PSQI}$ sleep latency subscale $(r=0.439, P=0.02)$ in $C$ (see Table). Partial correlations controlling for bone pain $(n=23 \mathrm{C}, \mathrm{n}=11 \mathrm{SA})$ found a statistically significant positive relationship between $25(\mathrm{OH}) \mathrm{D}$ and actigraphic sleep latency $(\mathrm{r}=0.426, \mathrm{P}=0 \cdot 048, \mathrm{n}=23)$ in $\mathrm{C}$ only. However, when adjusting for muscle pain $(n=21 \mathrm{C}, \mathrm{n}=8 \mathrm{SA})$, there were no significant associations between $25(\mathrm{OH}) \mathrm{D}$ and actigraphic sleep parameters in either ethnic group $(\mathrm{P}>0.05)$. Finally, there were no significant correlations between $25(\mathrm{OH}) \mathrm{D}$ and actigraphic sleep parameters when adjusting for outdoor light exposure (mins/d $>1000$ lux) $(\mathrm{P}>0.05, \mathrm{n}=20 \mathrm{C}, \mathrm{n}=8 \mathrm{SA})$.

\begin{tabular}{|c|c|c|c|c|c|c|c|}
\hline \multirow{2}{*}{\multicolumn{2}{|c|}{ Correlations ${ }^{\text {a }}$ Pearson's, ${ }^{\mathrm{b}}$ Spearman's }} & \multicolumn{3}{|c|}{ Caucasians (C) } & \multicolumn{3}{|c|}{ South Asians (SA) } \\
\hline & & $\mathrm{r}$ & $\mathrm{P}$ & $\mathrm{n}$ & $\mathrm{r}$ & $\mathrm{P}$ & $\mathrm{n}$ \\
\hline \multirow[t]{3}{*}{ Actigraphic $^{a^{*}}$} & Sleep duration & -0.036 & $0 \cdot 857$ & 27 & $0 \cdot 101$ & 0.732 & $\overline{14}$ \\
\hline & Log Sleep latency \pm & $0 \cdot 361$ & $0 \cdot 065$ & 27 & $-0 \cdot 562$ & 0.036 & 14 \\
\hline & $\%$ Sleep efficiency $¥$ & $-0 \cdot 012$ & $0 \cdot 951$ & 27 & $0 \cdot 223$ & 0.444 & 14 \\
\hline \multirow[t]{2}{*}{ PSQI $^{b^{b} * *}$} & Global score $\neq$ & $\mathbf{0} \cdot 385$ & 0.047 & 27 & $-0 \cdot 191$ & 0.496 & 15 \\
\hline & Sleep latency $\infty$ subscale & 0.439 & $0 \cdot 022$ & 27 & $-0 \cdot 140$ & $0 \cdot 618$ & 15 \\
\hline
\end{tabular}

$*_{n}=$ number of subjects with both valid actigraphic activity data for $\geqslant 7$ days and $25(\mathrm{OH}) \mathrm{D} * * \mathrm{n}=$ number of subjects with both valid a PSQI score and $25(\mathrm{OH}) \mathrm{D}$.

\pm Time taken to fall asleep, $¥ \%$ of time in bed that subject asleep. $\neq$ Overall sleep quality, higher score $=$ poorer sleep $\infty$ higher score $=$ longer time duration.

These findings suggest that higher $25(\mathrm{OH}) \mathrm{D}$ levels are associated with shorter actigraphic sleep latency in SA, but not when controlling for the confounders of musculoskeletal pain or light exposure. In $\mathrm{C}$, it is unclear why controlling for bone pain leads to the appearance of a relationship between $25(\mathrm{OH}) \mathrm{D}$ and sleep latency, and why participants with worse self-reported sleep (using PSQI) have better $25(\mathrm{OH}) \mathrm{D}$ status. These results are not easy to interpret, but suggest a potential mediating effect of ethnicity, musculoskeletal pain and light exposure in the relationship between $25(\mathrm{OH}) \mathrm{D}$ and both sleep latency and self-reported sleep quality. This interpretation is supported by previous studies showing a link between sleep problems and musculoskeletal pain ${ }^{3}$ and the fact that daytime light exposure is important to sleep health. Actigraphy, however, has known limitations in measuring sleep latency, and the number of subjects with valid light data were small. Further research in this area is warranted.

The D-FINES II study was supported by a PhD studentship for ALD from the University of Surrey.

1. Bertisch SM, Sillau S, de Boer IH, et al. (2015) Sleep 38(8):1305-11.

2. Massa J, Stone KL, Wei EK, et al. (2015) Sleep 38(2):251-7.

3. Chen Q, Hayman LL, Shmerling RH, et al. (2011) J Am Geriatr Soc. 59(8):1385-92. 